\title{
Assessment of the Regulatory Effect of Novel Indole-Core-Based Compound on Apoptosis and Cell Survival of Acute Myeloid Leukemia Cell Line
}

\author{
Parisa Heydari¹, Mojgan Noroozi-Karimabad 2,*, Zahra Sheikhrezaei ${ }^{1}$, Ali Darekordi³, Maryam Fekri Soofi Aadi, \\ Ahmad Fatemi ${ }^{5,1}$ and Gholamhossein Hasanshahi ${ }^{1,2^{*}}$

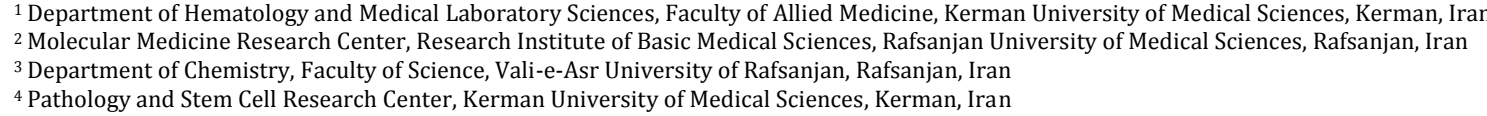

* Corresponding author: Mojgan Noroozi Karimabad, Molecular Medicine Research Center, Research Institute of Basic Medical Sciences, Rafsanjan University of Medical Sciences, Rafsanjan, Iran. Tel: +983431315000; Fax: +983431315003; Email: mojgan.noroozi@yahoo.com Gholamhossein Hasanshahi, Molecular Medicine Research Center, Research Institute of Basic Medical Sciences, Rafsanjan University of Medical Sciences, Rafsanjan, Iran. Tel: +983431315000; Email: ghassanshahi@gmail.com

Received 2021 January 29; Revised 2021 May 14; Accepted 2021 June 03.

\begin{abstract}
Background: Heterocyclic compounds are generally introduced as important valuable sources of pharmacologically active compounds. Amongst these compounds, the indole is largely distributed within the bioactive molecules, containing antitumor agents. Due to their unique physiochemical and biological properties, indole and its derivatives have been used as privileged scaffolds for designing antitumor agents.

Objectives: The current experimental study aimed to evaluate the anti-cancer effects of a novel compound with indole-core-base on acute myeloid leukemia (AML) cells.

Methods: Following being cultured, AML cells that had been multiplicities were treated by the demonstrated concentration of novel indole compounds (at doses of $100-300 \mu \mathrm{g} / \mathrm{mL}$ ) for $24 \mathrm{~h}$. The percentage of living and dead cells was subsequently determined by trypan bluedye (MERK, Germany). The survival rate of treated cells was also examined by MTT assay. The calculated fold changes of the studied genes expression against $\beta$-actin were determined by the real-time polymerase chain reaction (PCR) technique. The collected data were statistically analyzed by student t-test and repeated measure test.

Results: Results showed that the intended novel indole-core-based derivative (C18H10N2F60) followed both dose-dependent cytotoxic and anti-proliferative patterns on the AML cell line. The compound was able to induce apoptosis in $50 \%$ of the cells at the dose of $250 \mu \mathrm{g} / \mathrm{mL}$. Real-time PCR analysis indicated that in compound-treated cells the gene expression level of Bcl-2 has been downregulated, while Bax was upregulated, compared to untreated control cells.

Conclusion: Despite the lack of knowledge in this regard, in this study, results of this leading mechanism(s) that may run by the compound indicated that indole3carbaldehyde derivative has cytotoxic effects on AML cells in a dose-dependent fashion.

Keywords: AML, Apoptosis, C18H10N2F60, Indole, Leukemia
\end{abstract}

\section{Background}

Leukemia is characterized as the cancer of hematopoietic tissues, such as bone marrow and the lymphatic system. There exist several equivocations about the diagnosis and treatment of these disorders (1). Leukemia is clinically divided into two categories, namely chronic and acute. They are classified into two main subclasses based on their cellular origins; accordingly, the hematological malignancy is of acute myeloid leukemia (AML) and acute lymphoblastic leukemia (ALL) (2). The AML is a heterogeneous hematological disorder that immortally implicates myeloid precursors and is the most frequent leukemia in the early months of life $(3,4)$.

Acute promyelocytic leukemia (APL) is one of the AML subgroups which occurs at the age of 40-50 years and comprises $10-15 \%$ of total AMLs. Regularly, APL is caused by a myeloid lineage maturation defect that leads to the association of immature cells called promyelocyte. Nowadays, several types of therapeutic strategies, such as surgery, radiation, and chemotherapy, are introduced for AML. Since chemotherapy is associated with drug resistance and recurrence and is accompanied by toxicity effects on normal cells (5), this study aimed to investigate the efficacy of other compounds, like indole derivatives on AML cell lines (APL cells).

Heterocycles are noticeable for their biological effects and redundancy in natural products (6). Indole is one of these compounds with anticancer effects. Indoles are among the strongest elements of plants that affect cancers and other disorders $(7,8)$. It is well fitted into the category of aromatic heterocyclic organic compounds waving a bicyclic structure, containing a six-membered ring fusing with a five-membered nitrogen-containing pyrrole ring. Epidemiological reviews alongside animal-based studies have reported the beneficial and valuable effects of some novel indole-core-based reagents against tumorigenesis (9).

Indole derivatives have been reported to be able 
to limit the proliferation of several cancer cell lines, including breast $(10-13)$, colon $(14,15)$, prostate $(16,17)$, and endometrium (10) (18-22).

\section{Objectives}

Therefore, the present study aimed to examine pro- and anti-proliferative or apoptotic effects of indole-3-carboxaldehyde, as a newly synthesized indole-derivative (Figure 1.), on AML cells to investigate its efficacy on cellular apoptosis of these cells.

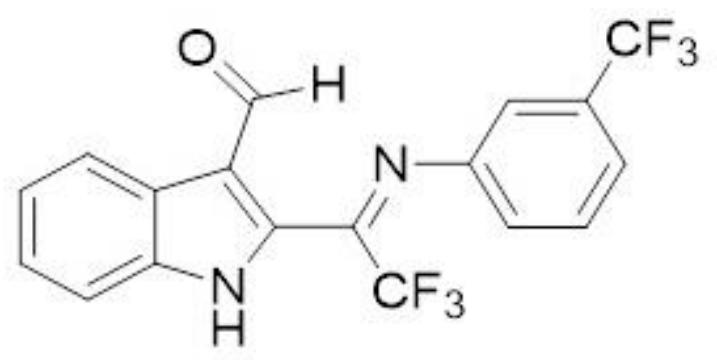

Figure 1. Chemical structure of C18H10N2F6O.

\section{Methods}

This case study was conducted in the laboratory of Kerman University of Medical Science, Kerman, Iran. The research and its tool were approved by the Research Ethics Committee of Kerman University of Medical Sciences, and ethical considerations were observed during the research.

\subsection{Cell culture}

The NB4 cell line as an AML-originated and lined cell was purchased from the Pasteur Institute of Iran (Tehran, Iran). The cells were simply cultured into RPMI 1640 media (Shellmax, Iran) which was supplemented with $10 \%$ fetal bovine serum (GibcoBRI, USA) and 2\% penicillin/streptomycin (Shellmax, Iran) in an atmosphere of CO2 (5\%) and 02 (95\%) at $37^{\circ} \mathrm{C}$ temperature.

\subsection{Compound treatment}

Once the cells reached the appropriate confluence (nearby70\%), they were treated by the novel indolecore-based derivative (C18H10N2F60) (Figure. 1) with various concentrations of 100, 150, 200, 250, and $300 \mu \mathrm{g} / \mathrm{mL}$. The drug stoke was prepared with $100 \mu \mathrm{L}$ dimethyl sulfoxide (DMSO) (MERK, Germany) as a solvent. Afterward, the working solution was made by the addition of $900 \mu \mathrm{L}$ RPMI media. For treatment, the cells were cultured in six well plates (SPL, South Korea). It should be mentioned that different doses were applied.

\subsection{Assessment of cell viability with trypan blue}

After $24 \mathrm{~h}$ of treatment, trypan blue was employed for checking the viability of the cells basically via the exclusion test. The dye $(50 \mu \mathrm{L})$ was added to $50 \mu \mathrm{L}$ of the cell suspension (in 1:1 ratio) and the living cells were counted using Neubauer chamber as they did not absorb trypan blue dye. The number of living cells was divided by the total number of cells and multiplied by 100 to calculate the percentage of total living cells. It should be noted that the experiment was performed in triplicate.

(Living cells/total cells) $\times 100=$ percentage of the living cells

\subsection{MTT assay}

The cellular metabolic activity was examined by MTT assay. For this purpose, the plate and cells were treated by intended doses in a 96-well plate, and the MTT powder (Sigma Aldrich, Germany) was added after $24 \mathrm{~h}$. The MTT solution was prepared in 10 $\mathrm{mg} / \mathrm{mL}$ phosphate-buffer saline concentration. A volume of $100 \mu \mathrm{L}$ of the resultant MTT solution was added to each well of the plate and the plate was covered properly by aluminum foil.

In the next step, $4 \mathrm{~h}$ after the incubation, the treated plates were centrifuged at $4000 \mathrm{rpm}$ for 7 min. The resultant supernatant liquid was drained out and $100 \mu \mathrm{L}$ of DMSO was further added to each well and pipetted for proper mixture and dilution of formazan crystals. In the next step, the light absorbance was determined by a spectrophotometer at $570 \mathrm{~nm}$ wavelength. Therefore, the cytotoxic dose in which the compound was able to destroy $50 \%$ of the cells (the IC50 dose) was evaluated. Analyses were performed in triplicate for each dose and the three following types of controls were also set: 1 ) cells only, 2) cells+DMSO (10\%), and 3) cells+DMSO+indole (for only 200, 250, and 300 $\mu \mathrm{g} / \mathrm{mL}$ doses). Accordingly, the toxicity of DMSO and indole alone was also investigated (23).

\subsection{Assessment of apoptosis by annexin V and PI flow cytometry}

Annexin $\mathrm{V}$ is a sensitive marker for the assessment of apoptotic cells which indicates the expression of phosphatidylserine on their surface. PI is a marker for the differentiation of apoptotic cells from necrotic ones which colors the nucleus. The next steps were performed using IC50 dose (250) alongside the control specimen. A number of $1 \times 10^{6}$ cells were seeded in $1 \mathrm{~mL}$ of phosphate-buffered saline in test tubes. These cells were treated with an IC50 dose $(250 \mu \mathrm{g} / \mathrm{ml})$ for $24 \mathrm{~h}$. It should be noted that the experiments were performed in triplicate.

\subsection{Extraction of total RNA and cDNA of generation}

The cellular total RNA content of cultured NB4 cells was extracted by Trizol reagent (Invitrogen, USA) based on the guidelines of the manufacturer. The RNA concentrations were determined by measuring the absorbance at $260 / 280 \mathrm{~nm}$ using a Nanodrop spectrophotometer. 


\section{7. cDNA Synthesis}

The cDNA was generated using the High Capacity cDNA Reverse Transcription Kit (Thermo \#K1622). Following completion of the cDNA synthesis processes, the resultant cDNA was stored at $-20{ }^{\circ} \mathrm{C}$ until use.

\subsection{Quantitative real-time polymerase chain reaction and gene expression}

The expression levels of target genes (Table 1) were analyzed by the application of SYBR Green I Master Mix polymerase chain reaction (PCR) (Genet Bio, Korea) using an ABI real-time PCR (RT-PCR) System (Applied Biosystems, USA). The Vector NTI software was also used to design the specific primers for $B c l-2, B a x$, and $\beta$-actin which were used as an endogenous control.

\subsection{Statistical analysis}

The collected data were statistically analyzed in SPSS software (version 18). All the experiments were performed three times for each individual sample and all of the obtained results were presented as the mean value of those three experiments. The data were also analyzed using student t-test and repeated measures while a p-value of less than 0.05 was considered statistically significant.

\section{Results}

\subsection{Trypan blue assay results}

The results indicated that the cell viability was considerably reduced in a dose-dependent fashion. The results of cell survival after $24 \mathrm{~h}$ of treatment by trypan blue are shown in Figure 2.

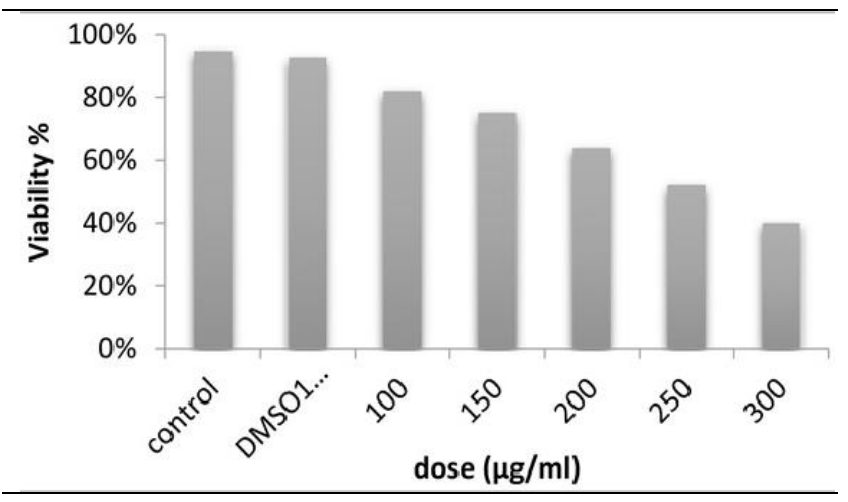

Figure 2. Results of cell survival concentration after $24 \mathrm{~h}$ of treatment by trypan blue. The results show that cell viability has reduced depending on dose amplification. All changes observed in the cell viability are significant $(\mathrm{P}<0.05)$.

\subsection{MTT assay results}

Results of the MTT assay indicated that at the dose of $250 \mu \mathrm{g} / \mathrm{ml}$, the novel indole derivative had cytotoxic effects which killed $51 \%$ of the AML cells. Overall, based on the results of the MTT assay, the cell viability was reduced in a dose-dependent fashion after $24 \mathrm{~h}$ of treatment (Figure 3).

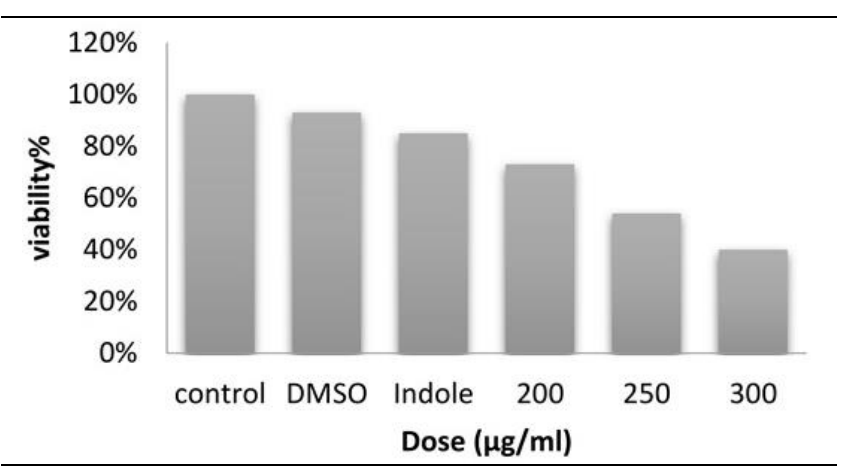

Figure 3. MTT assay results after $24 \mathrm{~h}$. The MTT assay results illustrate that in $250 \mu \mathrm{g} / \mathrm{mL}$ dose, indole derivative had cytotoxic effects which killed 51\% of AML cells. The results show that cell viability reduced in a dose-dependent fashion.

\subsection{Flow cytometry results}

After the statistical analysis of the data, the flow cytometry results revealed that increased apoptosis caused by the effect of the C18H10N2F60 compound was significant after $24 \mathrm{~h}$, compared to the control group (Figure 4).

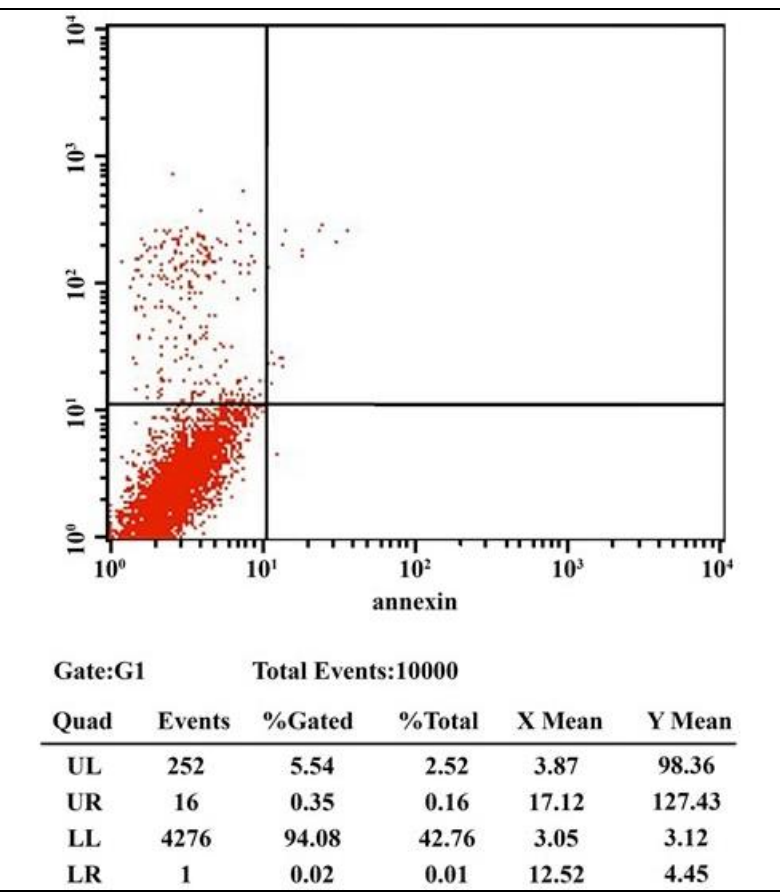

Figure 4. Flow cytometric cell viability and apoptosis. Based on the statistical analysis, the flow cytometry data revealed that an increase in apoptosis caused by the effect of the C18H10N2F60 compound was significant at $24 \mathrm{~h}$, compared to the untreated control group. After the treatment, the cells were stained with Annexin V and propidium iodide and then the apoptotic effect of the indole-core-based novel on cells was detected by flow cytometry. Flow cytometry results for IC50 dose (left picture) and the control (right picture). UL: upperleft, UR: upper-right, LR: lower-right, LL: lower-left.

\subsection{Amplification curves of cDNA samples of Bcl-2 and $\beta$-actin}

Amplification and melting curve analysis of quantitative RT-PCR for MICAL2, Bax, Bcl-2, and $\beta$ actin genes indicated that the amplification was performed in an appropriate manner (Figure 5). 
4.5. Melting curves of real-time polymerase chain reaction

According to the results of the melting curve for each separate primer, they acted as a special shape and also demonstrated any non-especial patches and secondary structures (Figure 6)

4.6. Effect of C18H10N2F6O on the expression of Bax and Bcl-2 genes

The quantitative RT-PCR data revealed that the expression of $B a x$ was substantially increased in the AML cells treated with C18H10N2F60 for $24 \mathrm{~h}$, compared to the untreated control cells $(\mathrm{P}<0.05)$ (Figure 7a). Inversely, the quantitative RT-PCR data revealed that the expression of $\mathrm{Bcl}-2$ was substantially decreased in AML cells treated to untreated C18H10N2F60 for $24 \mathrm{~h}$, compared with control cells. This is indicative of the fact that the expressions of both $\mathrm{Bax}$ and $\mathrm{Bcl}-2$ follow a time-dependent pattern $(\mathrm{P}<0.05)$ (Figure 7b).
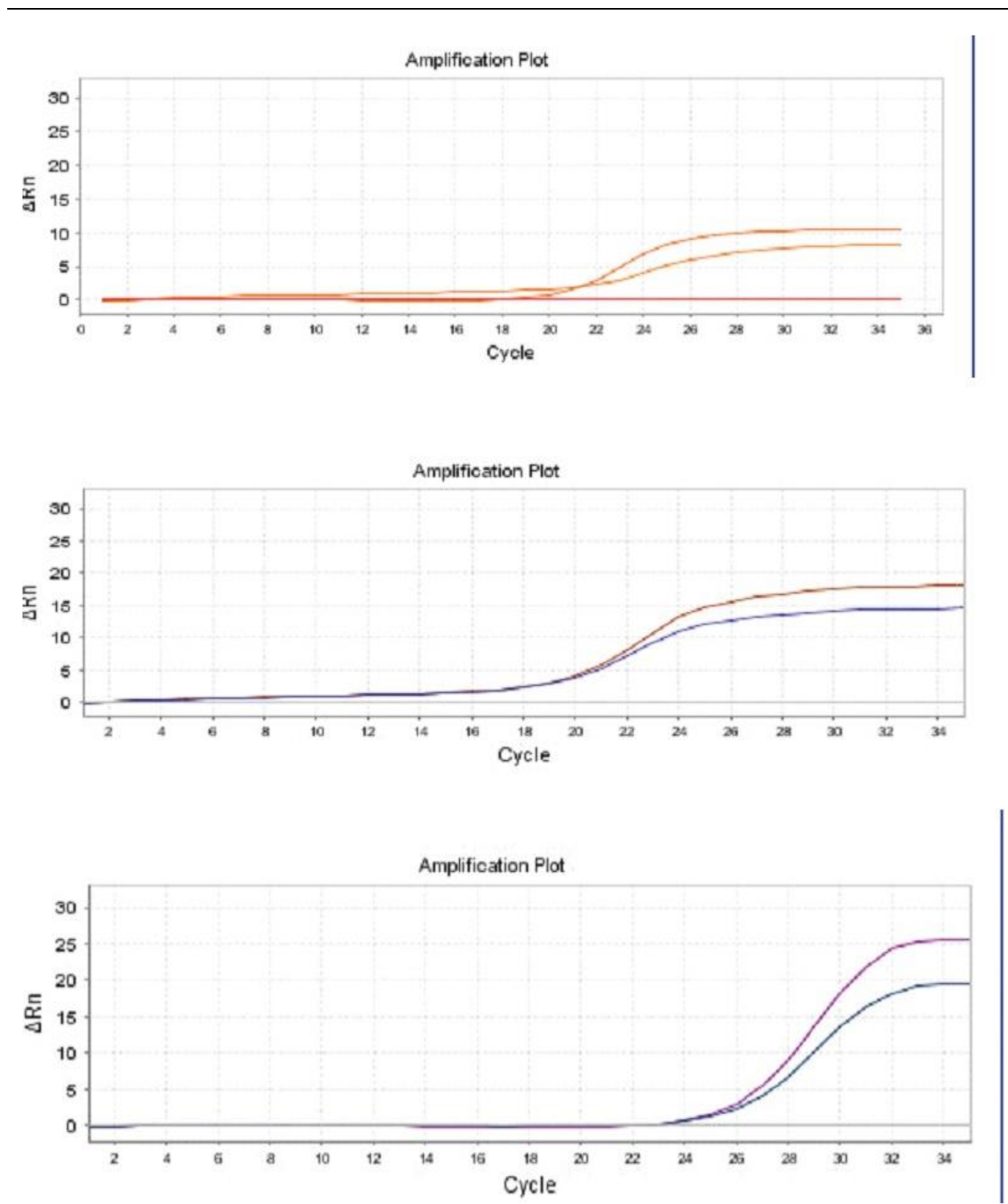

Figure 5. Diagram amplification and melting curve analysis of the real-time polymerase chain reaction analysis for Bax, Bcl-2, and $\beta$-actin genes.

a.Diagram of $\beta$-actin gene proliferation before and after 24 -h treatment with indole

b. Diagram of Bax gene amplification before and after 24-h treatment with indole c. Diagram of Bax gene amplification before and after 24-h treatment with indole

Table 1. Sequences of the e mployed primers in this study

\begin{tabular}{|c|c|c|}
\hline Primer & Forward (5' $\left.\rightarrow 3^{\prime}\right)$ & Reverse $\left(5^{\prime} \rightarrow 3 '\right)$ \\
\hline Bcl-2 & GGTGAACTGGGGGAGGATTG & CGTACAGTTCCACAAAGGCATC \\
\hline Bax & AGGATGCGTCCACCAAGAAG & CGGCCCCAGTTGAAGTTGC \\
\hline$\beta$-actin & GGGCATGGGTCAGAAGGATT & CGCAGCTCATTGTAGAAGGT \\
\hline
\end{tabular}




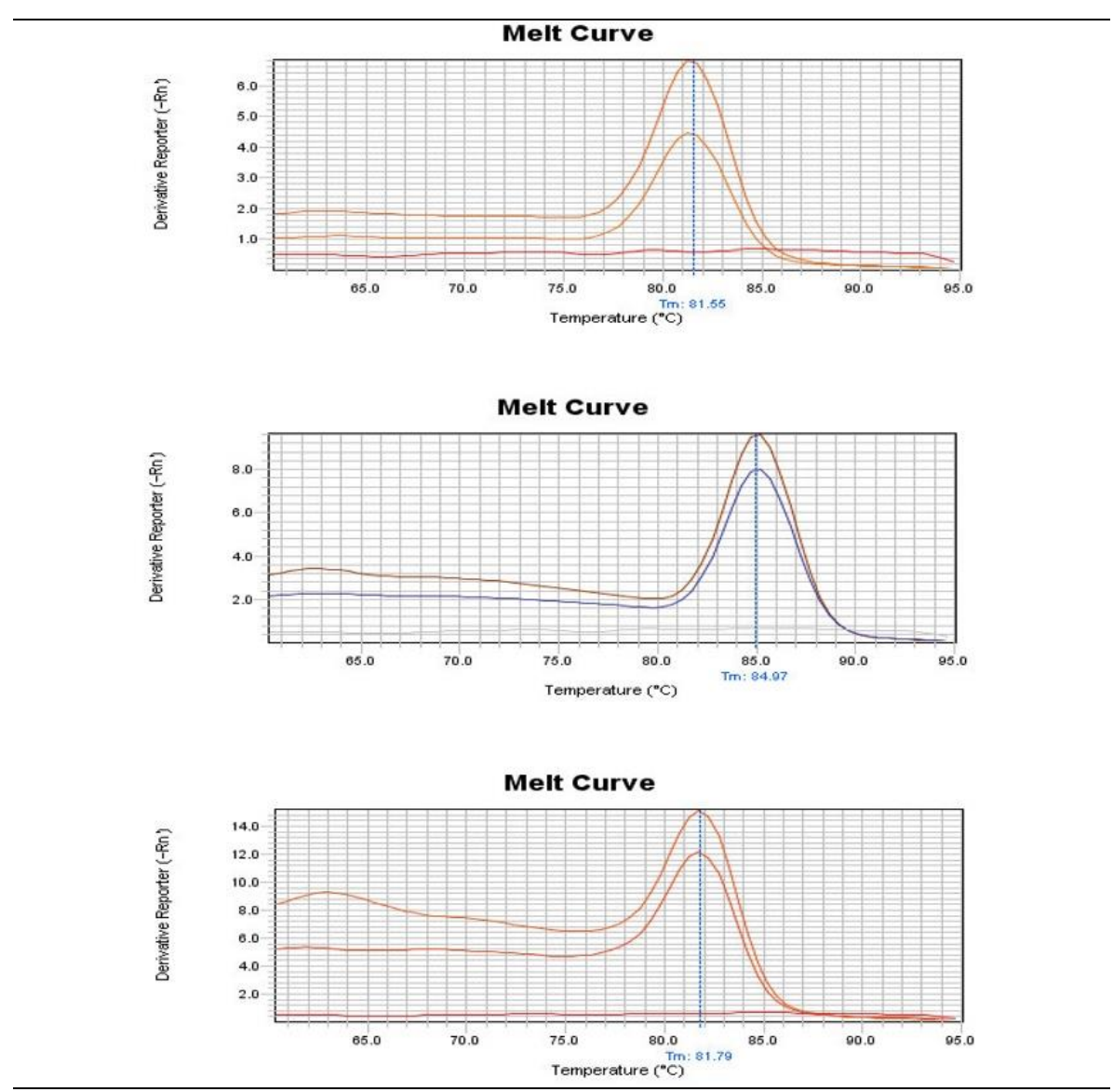

Figure 6. $\beta$-actin melting curve before and after 24 -h treatment with novel indole-core-based compound

a.Bax melting curve before and after 24-h treatment with novel indole-core-based compound b. Bcl-2 melting curve before and after 24-h treatment with novel indole-core-based compound
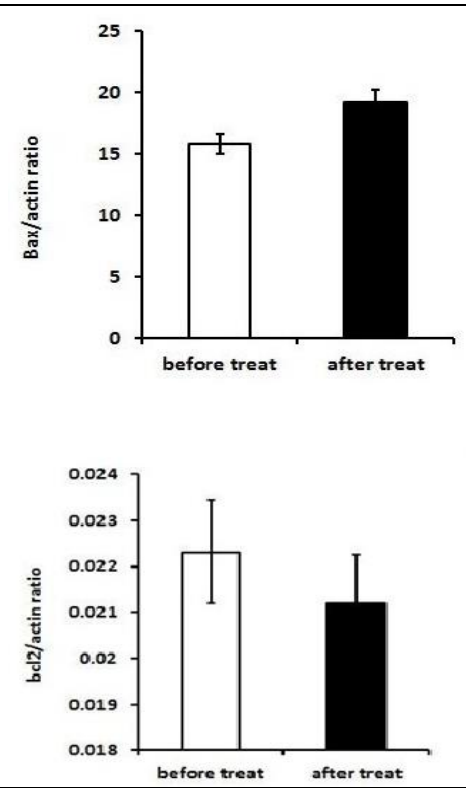

Figure 7. A. Results of Bax gene expression, as an anti-apoptotic gene before and after indole derivative treatment for $24 \mathrm{~h}$, compared to control cells at IC50 dose by real-time polymerase chain reaction.

B. Diagram of changes in $\mathrm{Bcl}$-2 gene expression as an anti-apoptotic gene before and after indole derivative treatment for $24 \mathrm{~h}$, compared to control cells at IC50 dose by real-time polymerase chain reaction. 


\section{Discussion}

As mentioned in the introduction, the blood malignancy of APL is one of the AML subgroups which was primarily named AML-M3 in French-AmericanBritish classification (24). Initially, daunorubicin (1973) was used as a chemotherapy reagent for APL patients. Thereafter, anthracycline combination (daunorubicin, idarubicin, and Ara-C) was introduced as the first-line treatment for APL. Moreover, in 1985, all-trans retinoic acid (ATRA) was released to the market as a new treatment for APL (25).

In early 1990, ATO prescription led to more satisfactory therapy of refractory and relapsed patients in addition to patients with primary APL (24). A therapeutic protocol was also established by the combination of ATRA and ATO which has resulted in increased survival of the patients with the primary diagnosis of APL (25). The ATO therapy protocol was successful; however, the further possibility of relapse was reported in some APL cases (26). The arsenic was also applied as a beneficial agent in relapse cases of APL (27); nonetheless, arsenic was not able to induce apoptosis on its own at lower doses, and it is very toxic and harmful for the healthy tissues (28).

In general, indole derivatives fit within the most important heterocyclic compounds in the field of drug-discovery studies. They are well known as a very important category of molecules, playing very important parts in cell biology. These main indole derivatives have been the subject of several research projects in multiple fields varying from the usage of bioactive molecules against microbes and cancer cells to various types of disorders in human studies worldwide. These types of indole inhibitory effects are regulated through the initiation of several intracellular signaling pathways.

Production of novel compounds with anticancer properties is a procedure through which cancer therapy may be achieved (29). Comprehension of the background molecular pathways that are involved and co-operate in the development of leukemia might possibly lead to the development of new therapeutic protocols to improve the survival rate of patients (30). The $B C L-2$ has been reported to be overexpressed in the AML subtypes of leukemia which might mean that it plays a fundamental role in both pathogeneses and the development of AML. Accordingly, as $B C L-2$ is the most well-known member of the paramount family members of apoptosis, gene group, and recent pieces of evidence have indicated that these family proteins, such as Bax, also play key roles in this phenomenon. (30).

The present study examined the effect of C18H10N2F60 on Bax and BCL-2 expression levels in AML cells. The results revealed that in $250 \mu \mathrm{g} / \mathrm{mL}$ dose, the indole derivative exhibited cytotoxic effects which resulted in killing $51 \%$ of the AML cells. These findings can confirm that the desired reduction of cellular viability is probably due to the fact that the viability reduction was associated with the compound in a dose-dependent fashion. It should be mentioned that this was also statistically confirmed by the RT-PCR. The RT-PCR revealed that the expression of Bax was substantially increased in AML cells treated with $\mathrm{C} 18 \mathrm{H} 10 \mathrm{~N} 2 \mathrm{~F} 60$, compared to the untreated control cells after $24 \mathrm{~h}$.

These achievements are possibly indicative of the fact that in addition to the dose, it has followed a time-dependent pattern as well (31). The anti-tumor properties of C18H10N2F60 are likely to be linked to its antioxidant activities. It has also been well established that this synthetic compound can prevent the activation of several enzymes and signals varying from cyclooxygenase, hydroperoxidase, protein kinase C, $B C L-2$ phosphorylation, Akt, a kinase binding position (focal adhesion kinase) to nuclear factor-kappa B (NF- $\kappa \mathrm{B})$, matrix metalloprotease-9, and cell cycle regulators.

Jazirehi and Bonavida (32) and Wei XN have indicated that $\mathrm{I} 3 \mathrm{C}$ has displayed inhibitory effects on protein expression of NF- $\mathrm{KB}$ pathway by employing a protein array method (33). In another research program, the researchers found that I3C induced the protein expression of caspase 8 . Overall, these results may indicate that the inhibition of the NF- $\mathrm{BB}$ pathway along with stimulation caspase 8 might be involved in the pro-apoptotic effect of I3C. In the TNF- $\alpha$ signaling pathway, the RIP1 is at the top of the upstream targets of the NF- $\kappa$ B signal. The K63 ubiquitination state also acts as a cell-death switch that responds to TNF signaling. The RIP1 ubiquitination is achieved by K63 and, in turn, the NF- $\mathrm{BB}$ survival pathway, whereas inversely, de-ubiquitinated RIP1 leads to caspase 8 stimulation and further triggers apoptosis (33).

It is now revealed that apoptosis plays a key role in the response to chemotherapy, which suggests a relationship between drug-induced apoptosis and therapeutic efficiency in leukemic patients (34) In this regard, the analysis of anti-apoptotic and proapoptotic genes can increase our knowledge of the key prognostic tool for expecting resistance to chemotherapy compounds (35). An alteration was reported in Bcl-2 (as an anti-apoptotic gene) and Bax (as a pro-apoptotic) genes expressions (by Bax and Bcl-2 ratio) subsequent to the stimulation of programmed death by some of the indole combinations in NB4 cell lines.

Finally, it can be concluded that this indole-corebased novel derivative $\left(\begin{array}{llll}\mathrm{C}_{18} & \mathrm{H}_{10} & \mathrm{~N}_{2} \mathrm{~F}_{6} \mathrm{O}\end{array}\right)$ may have antiproliferative and cytotoxic effects by inducing the apoptosis of AML cells. These effects are related to the different components of drugs, such as $\mathrm{CF}_{3}$. Accordingly, we believe that indole-3-carbaldehyde derivative could presumably be considered a multitargeted agent that appears to serve as a useful tool either as a single agent and/or as a combined formulation alongside conventional chemotherapeutic 
reagents to limit the processes of tumor progression in the treatment of human malignancies. However, we also believe that a future in-depth mechanistic in vitro research program, homologue to in vivo animal models and rationally designed novel clinical trials are highly needed for the better understanding of the value of these "natural products" in the field of treatment of human malignancies.

\section{Conclusion}

This project was limited due to financial issues and more funding was needed to examine the mechanisms involved in the effects of this novel derivative on apoptosis of AML-NB4 cells. For future studies, the authors are planning to use this derivative in in vivo models on animal/rodent models of leukemia.

\section{Acknowledgments}

This project was supported by a grant from the Rafsanjan University of Medical Sciences, Rafsanjan, Iran.

\section{Footnotes}

Conflicts of Interest: The authors declare no conflict of interest, financial or otherwise.

Ethics Approval and Consent to Participate: Not applicable.

Human and Animal Rights: No animals/humans were used for studies that are the basis of this research.

Consent for Publication: Not applicable.

Availability of Data and Materials:Not applicable. Funding:None.

\section{References}

1. Montagna D, Maccario R, Montini E, Tonelli R, Lisini D, Pagani S, et al. Generation and ex vivo expansion of cytotoxic $\mathrm{T}$ lymphocytes directed toward different types of leukemia or myelodysplastic cells using both HLA-matched and partially matched donors. Exp Hematol. 2003;31(11):1031-8. doi: 10.1016/s0301-472x(03)00230-3. [PubMed: 14585366].

2. Soodeh N, Fatemeh N, Ahmad K, Hossein D, Hossein R, Shahrbanoo R, et al. Effect of HESA-A on acute promyelocytic cell line (NB4). Payavard Salamat. 2012;6(3):67-76.

3. Longo DL, Fauci AS, Kasper D, Hauser S, Jameson J, Loscalzo J. Harrison's principles of internal medicine. New York: McGrawHill Companies; 2012. P. 3287.

4. McPherson RA, Pincus MR. Henry's clinical diagnosis and management by laboratory methods. New York: Elsevier Health Sciences; 2016.

5. Gottesman MM. Mechanisms of cancer drug resistance. Annu Rev Med. 2002;53(1):615-27. doi: 10.1146/annurev.med.53. 082901.103929. [PubMed: 11818492].

6. Darehkordi A, Rahmani F, Hashemi V. Synthesis of new trifluoromethylated indole derivatives. Tetrahedron Lett. 2013;54(35):4689-92. doi: 10.1016/j.tetlet.2013.06.093.

7. Celik I, Tuluce Y. Effects of indoleacetic acid and kinetin on lipid peroxidation and antioxidant defense in various tissues of rats. Pestic Biochem Physiol. 2006;84(1):49-54. doi: 10.1016/j.pestbp.2005.05.004

8. Karimabad MN, Mahmoodi M, Jafarzadeh A, Darekordi A, Hajizadeh MR, Hassanshahi G. Molecular targets, anti-cancer properties and potency of synthetic indole-3-carbinol derivatives. Mini Rev Med Chem. 2019;19(7):540-54. doi: 10.2174/1389557518666181116120145. [PubMed: 30444199].

9. Steinmetz KA, Potter JD. Vegetables, fruit, and cancer prevention: a review. J Am Diet Assoc. 1996;96(10):1027-39. doi: 10.1016/S0002-8223(96)00273-8. [PubMed: 8841165].

10.Weng JR, Tsai CH, Kulp SK, Chen CS. Indole-3-carbinol as a chemopreventive and anti-cancer agent. Cancer Lett. 2008; 262(2):153-63. doi: 10.1016/j.canlet.2008.01.033. [PubMed: 18314259].

11. Weng JR, Omar H, Kulp S, Chen CS. Pharmacological exploitation of indole-3-carbinol to develop potent antitumor agents. Mini Rev Med Chem. 2010;10(5):398-404. doi: 10.2174/13895571 0791330945. [PubMed: 20370707].

12. Telang N, Katdare M. Epithelial cell culture models for the prevention and therapy of clinical breast cancer (Review). Oncol Lett. 2012;3(4):744-50. doi: 10.3892/ol.2012.561. [PubMed: 22740986].

13. Ahmad A, Sakr WA, Rahman K. Mechanisms and therapeutic implications of cell death induction by indole compounds. Cancers. 2011;3(3):2955-74. doi: 10.3390/cancers3032955. [PubMed: 24212940].

14.Jafarian AH, Forooshani MK, Takallou L, Roshan NM. CD10 expression in gastric carcinoma is correlated with tumor grade and survival. Univ Med. 2019;38(1):41-7. doi: 10.18051/UnivMed.2019.v38.41-47.

15.Wang TT, Schoene NW, Milner JA, Kim YS. Broccoli-derived phytochemicals indole-3-carbinol and 3, 3'-diindolylmethane exerts concentration-dependent pleiotropic effects on prostate cancer cells: Comparison with other cancer preventive phytochemicals. Mol Carcinog. 2012;51(3):244-56. doi: 10.1002/mc.20774. [PubMed: 21520295].

16. Frydoonfar HR, McGrath DR, Spigelman AD. The effect of indole-3-carbinol and sulforaphane on a prostate cancer cell line. ANZ J Surg. 2003;73(3):154-6. doi: 10.1046/j.14452197.2003.02652.x. [PubMed: 12608980].

17.Goldberg A, Titorenko V, Beach A, Abdelbaqi K, Safe S, Sanderson J. Ring-substituted analogs of 3, $3^{\prime}$ diindolylmethane (DIM) induce apoptosis and necrosis in androgen-dependent and-independent prostate cancer cells. Investig New Drugs. 2014;32(1):25-36. doi: 10.1007/s10637013-9979-y. [PubMed: 23709189].

18. Aggarwal BB, Ichikawa $\mathrm{H}$. Molecular targets and anticancer potential of indole-3-carbinol and its derivatives. Cell Cycle. 2005;4(9):1201-15. doi: 10.4161/cc.4.9.1993. [PubMed: $16082211]$.

19. Aggarwal BB, Shishodia S. Molecular targets of dietary agents for prevention and therapy of cancer. Biochem Pharmacol. 2006;71(10):1397-421. doi: 10.1016/j.bcp.2006.02.009. [PubMed: 16563357].

20. Kim YS, Milner J. Targets for indole-3-carbinol in cancer prevention. J Nutr Biochem. 2005;16(2):65-73. doi: 10.1016/ j.jnutbio.2004.10.007. [PubMed: 15681163].

21. Kim YS, Milner JA. Bioactive food components and cancerspecific metabonomic profiles. Biomed Res Int. 2010;2011: 721213. doi: 10.1155/2011/721213. [PubMed: 21113295].

22. Rogan EG. The natural chemopreventive compound indole-3carbinol: state of the science. In Vivo. 2006;20(2):221-8. [PubMed: 16634522].

23. Karimabad MN, Mahmoodi M, Jafarzadeh A, Darehkordi A, Hajizadeh MR, Khorramdelazad H, et al. Evaluating of OCT-4 and NANOG was differentially regulated by a new derivative indole in leukemia cell line. Immunol Lett. 2017;190:7-14. doi: 10.1016/j.imlet.2017.06.012. [PubMed: 28690187].

24. Wang ZY, Chen Z. Acute promyelocytic leukemia: from highly fatal to highly curable. Blood. 2008;111(5):2505-15. doi: 10.1182/blood-2007-07-102798. [PubMed: 18299451].

25. Biondi A, Testi AM, Gibson BE. Acute promyelocytic leukaemia Mol Targeted Ther Childhood Cancer. 2010;9(5):83-108. doi: 10.1007/978-0-387-69062-9_5.

26. Alimoghaddam K. A review of arsenic trioxide and acute 
promyelocytic leukemia. Int J Hematol Oncol Stem Cell Res. 2014;8(3):44-54. [PubMed: 25642308].

27. Rego EM, de Santis GC. Differentiation syndrome in promyelocytic leukemia: clinical presentation, pathogenesis and treatment. Mediterr J Hematol Infect Dis. 2011;3(1): e2011048. doi: 10.4084/MJHID.2011.048. [PubMed: 22110898].

28. Mo J, Xia Y, Ning Z, Wade TJ, Mumford JL. Elevated human telomerase reverse transcriptase gene expression in blood cells associated with chronic arsenic exposure in Inner Mongolia, China. Environ Health Perspect. 2009;117(3):354-60. doi: 10.1289/ehp.11532. [PubMed: 19337508].

29. Kim DJ, Reddy K, Kim MO, Li Y, Nadas J, Cho YY, et al. (3Chloroacetyl)-indole, a novel allosteric AKT inhibitor, suppresses colon cancer growth in vitro and in vivo. Cancer Prev Res. 2011;4(11):1842-51. doi: 10.1158/1940-6207.CAPR11-0158. [PubMed: 21885813].

30. Yang SM, Tsai KD, Wong HY, Liu YH, Chen TW, Cherng J, et al. Molecular mechanism of Cinnamomum verum component cuminaldehyde inhibits cell growth and induces cell death in human lung squamous cell carcinoma NCI-H520 cells in vitro and in vivo. J Cancer. 2016;7(3):251-61. doi: 10.7150/jca.13689. [PubMed: 26918037].

31.Ping J, Gao AM, Qin HQ Wei XN, Bai J, Liu L, et al. Indole-3carbinol enhances the resolution of rat liver fibrosis and stimulates hepatic stellate cell apoptosis by blocking the inhibitor of kappaB kinase alpha/inhibitor of kappaBalpha/nuclear factor-kappaB pathway. J Pharmacol Exp Ther. 2011;339(2):694-703. doi: 10.1124/jpet.111.179820. [PubMed: 21862660].

32. Wu P, Shi KJ, An JJ, Ci YL, Li F, Hui KY, et al. The LEF1/CYLD axis and cIAPs regulate RIP1 deubiquitination and trigger apoptosis in selenite-treated colorectal cancer cells. Cell Death Dis. 2014;5(2):e1085. doi: 10.1038/cddis.2014.13. [PubMed: 24577083].

33. Li B, Cong M, Zhu Y, Xiong Y, Jin W, Wan Y, et al. Indole-3carbinol induces apoptosis of hepatic stellate cells through K63 de-ubiquitination of RIP1 in rats. Cell Physiol Biochem 2017;41(4):1481-90. doi: 10.1159/000470650. [PubMed: $28395284]$

34.Sun X, Bao J, Nelson KC, Li KC, Kulik G, Zhou X. Systems modeling of anti-apoptotic pathways in prostate cancer: psychological stress triggers a synergism pattern switch in drug combination therapy. PLoS Comput Biol. 2013;9(12):e1003358. doi: 10.1371/journal.pcbi.1003358. [PubMed: 24339759].

35.Zhang X, Bi L, Ye Y, Chen J. Formononetin induces apoptosis in $\mathrm{PC}-3$ prostate cancer cells through enhancing the $\mathrm{Bax} / \mathrm{Bcl}-2$ ratios and regulating the p38/Akt pathway. Nutr Cancer. 2014;66(4):656-61. doi: 10.1080/01635581.2014.894098. [PubMed: 24666255]. 